\title{
ULTRASONIC BIRD REPELLER FOR AVIATION
}

\author{
M Surya, Namita L Rao, Pratham Kumar D \\ Department of Electronics and Communication \\ Kammavari Sangham Institute of Technology \\ No.14, Raghuvanahalli, Kanakapura Road \\ Bengaluru-560109, India
}

\begin{abstract}
Birds are often considered to be outstanding indicators of the health of the overall environment [6]. A bird strike is strictly defined as a collision between a bird and an aircraft which is in flight or on a takeoff or landing roll. The term is often expanded to cover other wildlife strikes - with bats or ground animals [8].Indian airports have recorded a steady increase in number of bird hits and aircraft run-ins with stray animals over at least the past five years, according to official data, illustrating the potential safety risks and losses the aviation industry confronts from such accidents as the fleet of planes operated by domestic airlines expands rapidly [7] .In 2018, the number of bird hits and animal strikes was 1,244 , compared with 1,125 in 2017, 839 in 2016, 764 in 2015 and 719 in 2014, according to Directorate General of Civil Aviation (DGCA) data provided in response to a Right to Information (RTI) application filed by Hindustan Times [7]. It was 4.82 in 2018, down from 4.98 in 2014, a DGCA official said on condition of anonymity [7].

To overcome this problem, we are going to use "Ultrasonic radiation" "that will be radiated during the flight takeoff and landing which disturbs the birds (without harming them) and also not affecting the pilots during their flight.
\end{abstract}

Keywords: bird strike, flight take-off and landing, ultrasonic radiation

\section{INTRODUCTION}

Birdsare readily affected by physical and chemical impacts on their ecosystems, whether these are caused by natural or man-made influence [6]. Because many species of birds have become specialized to occupy certain niches and together, they inhabit almost every conceivable habitat, they are responsive to a wide variety of environmental changes and can reflect diversity and trends in other animals and plants with which they coexist. Unlike some other groups of animals that are also good environmental indicators, birds are relatively easy to observe and identify, and most are active during the day [6].

Bird strikes may occur during any phase of flight but are most likely during the take-off, initial climb, approach and landing phases due to the greater numbers of birds in flight at lower levels. Since most birds fly mainly during the day, most bird strikes occur in daylight hours as well.

The nature of aircraft damage from bird strikes, which is significant enough to create a high risk to continued safe flight, differs according to the size of aircraft [8].

Complete Engine failure or serious power loss, even on only one engine, may be critical during the take-off phase for aircraft [8].

Taking into heed to the above matter, different approaches were taken into consideration for improving the harmful effects caused to both birds and the aircraft.

The different approaches for repelling the birds were:

a. Propane scare cannons are one of the most common types of bird scaring device. The audible bang can reach very loud volumes, in excess of 150 decibels, causing a flight reaction in birds. Propane scare cannons are very loud and can be disruptive to people living nearby [9].

b. Cartridge scaring device include a wide variety of noise-producing cartridges usually fired from rockets or rope bangers, or on aerodromes from modified pistols or shotguns, which produce a loud bang and emit flashes of light [9].

c. The use of lasers can be an effective method of bird scaring, although there is some evidence to suggest some birds are "laser-resistant". As the effectiveness of the laser decreases with increasing light levels, it is likely to be most effective at dawn and dusk [9].

d. Present method used by pilots to send away birds is switching on the lights while take-off and landing phases of flying.

All the above-mentioned methods were not effective due to various reasons. Hence another effective method was using the "ultrasonic radiation" repelling the birds using radiation in the frequency range (20 to $30 \mathrm{kHz})$ which disturbs the birds (without harming) and repels them. This 


\section{International Journal of Engineering Applied Sciences and Technology, 2020 \\ Vol. 5, Issue 1, ISSN No. 2455-2143, Pages 163-166 \\ Published Online May 2020 in IJEAST (http://www.ijeast.com)}

paper will describe the usage of ultrasonic radiation which will proceed to be a repellent that generates a frequency between $20-30 \mathrm{kHz}$, so the bird will be disturbed.

- $\quad$ Speed of an aero plane during take-off: 240-285 $\mathrm{km} / \mathrm{hr}$.

- Speed of ultrasonic waves in air- $1108 \mathrm{~km} / \mathrm{hr}$.

As ultrasound travels faster than speed of the air plane it can be used to repel the birds just after take-off and before landing. To produce these frequencies, we are going to design the LC oscillator circuit. The oscillator circuit is a circuit that produces oscillations of electrical circuits. The ultrasonic digital deterrent system, have limited coverage, and takes slow effect therefore ultrasonic sensors which are widely used in controlling birds at airports and farms, will be using four piezo speakers were place in $90^{\circ}$ to each other to provide a $360^{\circ}$ area coverage for a crop field.

- $\quad$ Range of ultrasonic device - 50 feet (15 meter).

For real time applications we need to design a device which covers a distance of $10 \mathrm{~km}$.

\section{METHODOLOGY}

Ultrasonic waves are generated by transducer that includes a piezoelectric crystal that converts electrical energy (electric current) to mechanical energy (sound waves).[9]

Ultrasound are signal that operates at a frequency more than $20 \mathrm{kHz}$. It is not audible to human ears but it can create a disturbing environment for birds and pests.[4]

Ultrasonic repellents create a necessity in aeronautical institutes during the take-off and landing periods of aircrafts. Due to air strikes caused creates an imbalance in the eco system destroying the bird life. It also affects the aircraft infrastructure.

Looking forward to the size of the aircraft, a single speaker for emitting ultrasonic waves does not satisfy the needs. Hence, phased array in the context of an array of ultrasonic speakers is steered to point in different directions without moving the speakers [4]. A phasedarray transducer has a small footprint, but the ultrasound beam is steered electronically to produce a sufficiently wide far field of view. The ultrasound beam diverges from virtually the same point in the transducer [10].

The PA probe consists of many small ultrasonic transducers, each of which can be pulsed independently. By varying the timing, for instance by making the pulse from each transducer progressively delayed going up the line, a pattern of constructive interference is set up that results in radiating a quasi-plane ultrasonic beam at a set angle depending on the progressive time delay [10].

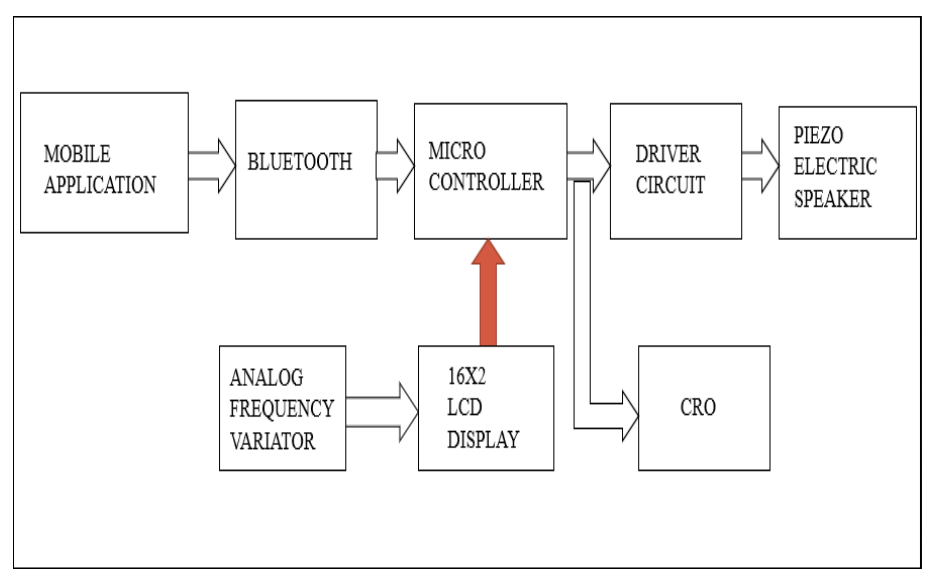

Figure 1. Block Diagram of the repelling device

When the aircraft begins to ascend or descend a manual switch is turned on (present on-board the aircraft) to start the ultrasonic radiations to the preferred range.

\section{Generation of Frequency}

i. The ultrasonic frequencies are produced using the microcontroller pic 18.

ii. A PWM generation is involved in developing the frequency.

iii. Since all the birds do no react to the same frequency two methods are proposed to vary frequency.

a. Digital Method: A mobile application is developed for varying the frequencies with decimal variation. This application is interfaced through a Bluetooth to the microcontroller.

b. Analog Method: Push buttons are used for increasing or decreasing the frequency by one step and displaying the frequency on an LCD.

\section{Radiating the Frequency}

i. A piezo electric speaker is used to radiate frequency generated.

ii. A driving circuit hence helps in connecting microcontroller and the speaker. 


\section{International Journal of Engineering Applied Sciences and Technology, 2020 \\ Vol. 5, Issue 1, ISSN No. 2455-2143, Pages 163-166 \\ Published Online May 2020 in IJEAST (http://www.ijeast.com)}

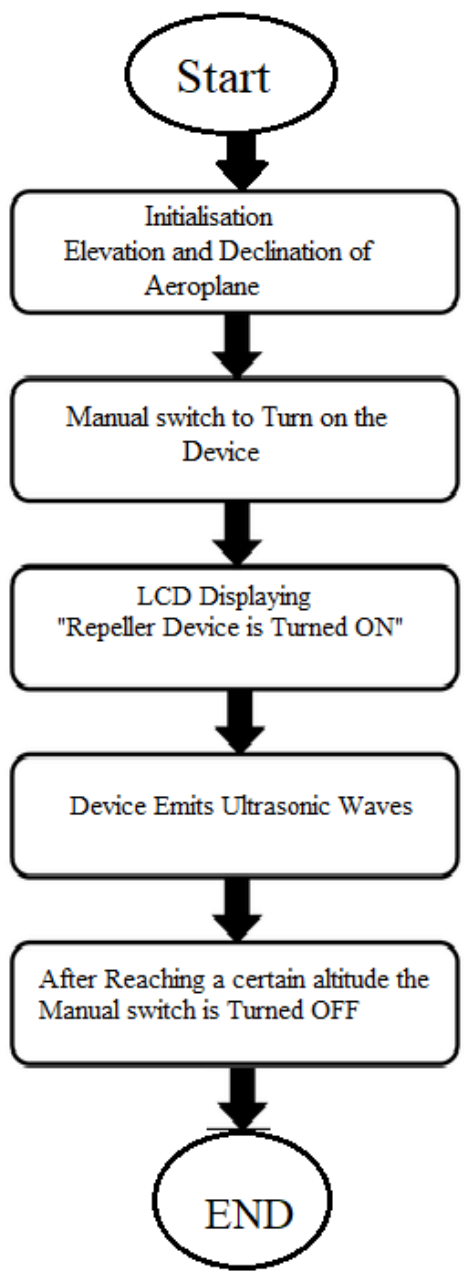

Figure 2: Flowchart of the repelling device to be implemented

With reference to figure 2, the elevation or declination of an aircraft is the crucial period of occurrence of an air strike. This necessitates the presence a repelling situated on the aircraft.

The presence of a manual switch on board the air craft switches on the device. Once the device is turned $\mathrm{ON}$, it emits ultrasonic radiation disturbing the birds and creating discomfort to them so that they do not make an attempt to move around the desired area.

After reaching a certain altitude with reference to takeoff or reaching the land surface with reference to landing the device must be turned off with the help of the manual switch.

\section{STAGES OF WORKING OF THE DEVICE}

Stage 1: Device to be turned on during Take-Off or landing

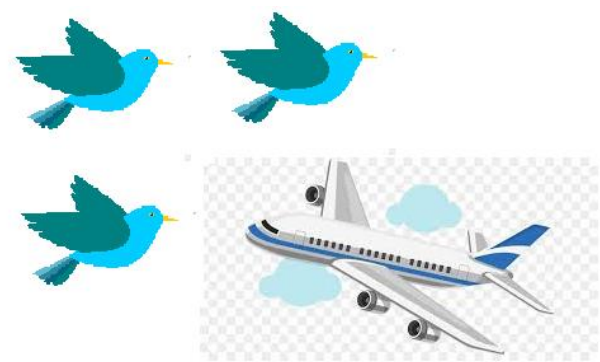

Stage 2: Generation of ultrasonic waves

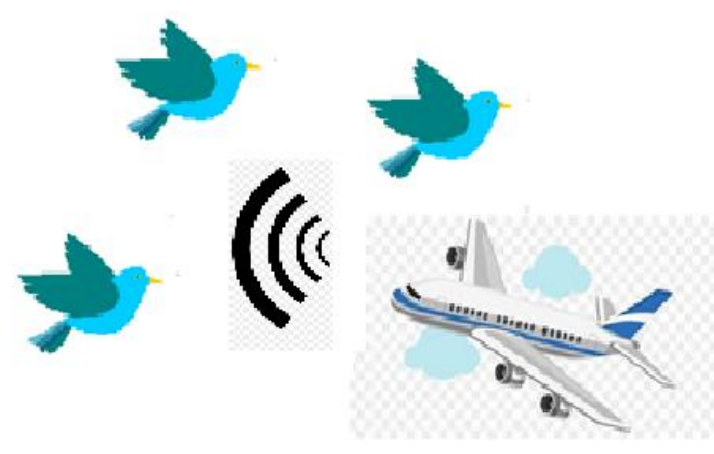

Stage 3: Repelling of Birds

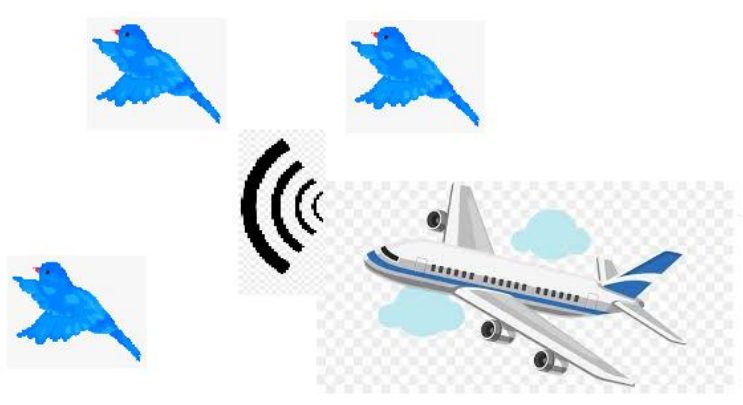




\section{International Journal of Engineering Applied Sciences and Technology, 2020 \\ Vol. 5, Issue 1, ISSN No. 2455-2143, Pages 163-166 \\ Published Online May 2020 in IJEAST (http://www.ijeast.com)}

\section{CONCLUSION}

The above proposed method will be effective with proper delivery of frequencies to be generated. For real-time purpose (i.e. device on the aircraft) must radiate these frequencies with enormous power for effective results.

\section{ACKNOWLEDGMENT}

This research was completely supported by our college, Kammavari Sangha Institute of Technology, Bangalore under the guidance of Mr. Santosh Kumar B.R, Associate Professor, ECE Department, KSIT.

\section{REFERENCES}

[1] Jaiye Jehoshaphat Dukiya, Vimal Gahlot(25 October 2012 ), "An Evaluation of Bird Strikes on Flight Safety Operations at International Airports".

[2] Fuliang Le, Jiawei Luo, Gongping Wu,(2009) "An Uninterrupted Bird Repeller on Transmission Line", Proceedings of the 2009 IEEE International Conference on Robotics and Biomimetics, China.

[3] Yahot Siahaan, Bheta Agus Wardijono and Yulisdin Mukhlis(2017), "Design of Birds Detector and Repellent Using Frequency Based Arduino Uno with Android System".

[4] Navinesshani Permal, Thiviya Barathi Raja Segaran, Renuga Verayiah, Farrukh Hafiz Nagi, Agileswari K. Ramasamy(2019), "Hardware Implementation of Beam Formed Ultrasonic Bird Deterrent System", IEEE 4th International Conference on Computer and Communication Systems.

[5] V. Arun pandiyan, J. Murugan Senthamilan, D. Uday Kumar, V. Vinithkumar(March 2019)), "Fabrication of Mobile Ultrasonic Bird Repeller" International Journal of Innovative Research in Advanced Engineering (IJIRAE) Issue 03, Volume 6.

[6]http://www.birdlife.org.au/conservation/science/threat s-to-birds

[7]https://www.hindustantimes.com/india-news/casesinvolving-stray-animals-bird-hit-rise-over-fiveyears/story
[8]https://www.skybrary.aero/index.php/Bird_Strike_htt ps://www.icao.int/MID/Documents/2018/WHMC

[9] https://en.m.wikipedia.org/wiki/Bird_scare

[10]https://en.wikipedia.org/wiki/Phased_array_ultrasoni cs 